\title{
Genetic parameter estimates for pre-weaning growth traits in Dorper sheep
}

\author{
F.W.C. Neser", G.J. Erasmus and J.B. van Wyk \\ Dept of Animal Science, University of the Orange Free State, PO Box 339, Bloemfontein, 9300 \\ "Email: Neser@landbou.uovs.ac.za
}

\section{Introduction}

Presently the Dorper is the second most populous sheep breed in South Africa and is exported to a number of countries such as the United States of America and Australia. A limited number of the Dorper flocks in South Africa have performance and parentage records. The flock from the Glen Agricultural Institute was used in this study, since complete and accurate record keeping was practiced for the past 16 years. The Dorper is normally marketed as soon as possible after weaning. Pre-weaning growth traits are therefore an important indication of the profitability of any Dorper enterprise. The object of this study was to estimate parameters for birth weight (BW), 42-day weight $(42 \mathrm{~W})$ and weaning weight $(\mathrm{WW})$ in the flock.

\section{Material and Methods}

A total of 4217 records, spanning 16 years, were obtained from the Dorper flock at the Glen Agricultural Institute near Bloemfontein in the Free State. The flock comprises 300 breeding ewes. An extensive management system, with an autumn mating season, is practiced. After editing, 3549 birth weight, 2889 42-day weight and 2836 weaning weight records were available for analysis. The DFREML 3.0 program of Meyer (1998) was used to estimate genetic parameters for the three traits simultaneously.

\section{Results and Discussion}

The genetic parameter estimates obtained for the three traits are presented in Table 1.

Table 1. Genetic parameter estimates for birth weight, 42-day weight and 100-day weight.

\begin{tabular}{lccc}
\hline Parameter & Birth weight & 42-day weight & 100-day weight \\
\hline Direct heritability & 0.109 & 0.276 & 0.198 \\
Maternal heritability & 0.096 & 0.100 & 0.095 \\
Permanent maternal environment & 0.115 & 0.108 & 0.082 \\
Total heritability & 0.211 & 0.169 & 0.127 \\
Correlation between animal effects & 0.349 & -0.633 & -0.578 \\
\hline
\end{tabular}

Five South African studies (Campbell, 1971; Fourie \& Heydenrych, 1982; Badenhorst et al., 1991; Van Wyk et al., 1993; Snyman et al., 1995) investigated birth weight in sheep. Unfortunately, only one of these studies was done on Dorper sheep. Also, only one (Snyman et al, 1995) of these studies included permanent maternal environment in the model. The direct heritability estimates of these studies varied between 0.16 and 0.30 , while the maternal heritability estimates varied between 0.09 and 0.43 . Results from the present study are, in general, lower for both direct and maternal heritability than the reported South African literature values. The one exception is the estimate of the maternal heritability, which correspond to that obtained by Snyman et al., (1995) (0.096-present study vs 0.09 ). The direct and maternal heritability estimates for birth weight obtained in this study is well within the scope of international results in the literature, although at the lower end of the scale (Tosh \& Kemp, 1994; Fogarty, 1995; Snyman et al., 1995; Mousa et al., 1999; Okut et al., 1999). Permanent maternal environment in birth weight could be attributed to the uterine environment provided by the dam as well as the effect of multiple births, which are quite common in this breed. The $\mathrm{c}^{2}$ estimate for permanent maternal environment in the present study is higher than both the direct and maternal heritability ( 0.115 vs 0.108 and 0.955$)$. It is, however, in line with results obtained by Snyman et al. (1995) (0.12) and higher than those obtained by Mousa et al. (1999) (0.09). The results in the literature that deal with the genetic correlation between the animal effects (direct and maternal) in birth weight vary. Results obtained by Burfening \& Kress (1992), Tosh \& Kemp (1994) and Mousa et al. (1999) varied between -0.74 and 0.01 . The correlation estimates in the literature are in general negative. A correlation estimate of 0.349 was found in the present study. Only one South African study (Neser et al., 2000) deals with 42 day weight. The direct and maternal heritabilities in the present study is substantially lower than those obtained by 
Neser et al. (2000) in SA Mutton Merino sheep (0.276 vs 0.366 direct and 0.100 vs 0.249 maternal). It is, however, more in line with the results obtained for 50-day weight in the same study (0.278 and 0.129). Other results in the literature varied between 0.05 and 0.21 for direct heritability and 0.05 and 0.19 maternal heritability (Shrestha et al., 1985; Shrestha et al., 1986; Tosh \& Kemp, 1994; Mousa et al., 1999). The genetic correlation between the animal effects for 42-day weight in the study is high and negative (-0.63). Results in the literature varied between 0.39 and -0.90 (Tosh \& Kemp, 1994; Notter,1998; Mousa et al., 1999; Neser et al., 2000). The high negative correlation is an indication of how difficult it is to simultaneously improve both these traits in a selection program. The permanent maternal environment effect on 42-day weight is mainly determined by the milk production of the dam. In this study the $c^{2}$ estimate was higher than that of maternal heritability. This could be an indication of the large influence the environment has on milk production. Only weaning weight were used in the two previous studies, that utilized mixed model methodology to estimate genetic parameters in this breed (Neser et al., 1994; Neser et al., 1995). Unfortunately neither these studies included permanent maternal environment. The results of the studies varied from $0.05-0.30$ for direct and $0.07-0.20$ for maternal heritability. This is in line with the results obtained in the present study (0.198 direct and 0.095 maternal). Published South African heritability estimates for weaning weight in other breeds vary from $0.11-0.33$ for direct and $0.07-0.20$ for maternal effects (Van Wyk et al., 1993; Snyman et al., 1995; Neser et al., 1998; Gray et al., 1999; Neser et al., 2000). Other heritability estimates for weaning weight in the literature for mutton and dual purpose breeds vary between 0.05 and 0.57 (Fogarty, 1995). The estimate for permanent maternal environment declined with age. Similar results were obtained by Tosh \& Kemp, (1994) in Hampshire, Polled Dorset and Romanov sheep and Neser et al. (2000) in SA Mutton Merino sheep. The correlation between the animal effects, as in the study of Neser et al. (2000), also declined with age. The correlation is, however, still high and negative $(-0.58)$. This correspond with results obtained in the literature (Neser et al., 1998; Notter, 1998; Gray et al., 1999; Mousa et al., 1999; Neser et al., 2000). Only one study in the literature (Tosh \& Kemp, 1994 - Romanov sheep) could be found that produced a positive correlation between the animal effects. In the same study, in two different sheep breeds (Hampshire and Polled Dorset), negative correlation estimates between maternal and direct effects were found. Fogarty (1995) reported a weighted average genetic correlation estimate between birth and weaning weight of 0.39 . This is higher than the results obtained by Maria et al. (1993) (0.12) but lower than those obtained by Mousa et al. (1999) (0.45). The results in the present study are low (0.269), indicating that it is possible to improve weaning weight without significant increases in birth weight $(0.513$ and 0.590$)$. Both birth and weaning weight have a moderate genetic correlation estimate with 42 -day weight. The maternal genetic correlation between weaning weight and 42-day weight is high (0.706) and moderate between birth - and 42-day weight (0.417) and birth- and weaning weight (0.541). Selection for weaning weight will therefore lead to an improvement in both the other two traits.

The permanent maternal environmental correlation between the different weight varies between moderate and high. This could be due to a carry over effect, especially between 42-day- and weaning weight and the many multiple births that do occur in the breed.

\section{Conclusions}

It is unfortunate that data from only one flock could be used in this study. The stud breeders should be encouraged to be more precise with record keeping in the breed. If records from more studs were available, more accurate parameters and breeding values for the breed could be estimated that could greatly assist selection decisions.

\section{References}

Badenhorst M.A. et al., 1991. S. Afr. J. Anim. Sci. 21, 162.

Burfening, P.J. \& Kress, D.D., 1993. Small Rumin. Res. 10, 153.

Cambell, Q.P., 1971. PhD thesis. University of Orange Free State, Bloemfontein.

Fourie, A.J. \& Heydenrych, H.J., 1982. S. Afr. J. Anim. Sci. 12, 61.

Fogarty, N.M., 1995. Anim Breed. Abstr. 63, 101.

Gray, H.Q. et al., 1999. S. Afr. J. Anim. Sci. 29, 48.

Maria, G.A. et al., 1993. J. Anim. Sci. 71, 845.

Meyer, K., 1998. User notes.

Mousa, E. et al., 1999. J. Anim. Sci. 77, 1659.

Neser F.W.C. et al., 1994. S. Afr. J. Anim. Sci. 24,77.

Neser F.W.C. et al., 1995. S. Afr. J. Anim. Sci. 25, 179. 
Short paper and poster abstracts: $38^{\text {th }}$ Congress of the South African Society of Animal Science Neser F.W.C. et al., 2000. S. Afr. J. Anim. Sci. (Submitted).

Notter, D.R., 1998. Livest. Prod. Sci. 55, 205.

Okut, H. et al., 1999. J. Anim Sci. 77, 2372.

Snyman, M.A. et al., 1995. Livest. Prod. Sci. 44, 229.

Shrestha, J.N.B. et al., 1985. Can. J. Anim. Sci. 65, 575.

Shrestha, J.N.B. et. al., 1986. Can. J. Anim. Sci. 66, 289.

Tosh, J.J. \& Kemp, R.A., 1994. J. Anim. Sci. 72, 1184.

Van Wyk, J.B. et al.,1993. S. Afr. J. Anim. Sci. 23, 72. 